\title{
Research on the Development of Smart Grid
}

\section{Qi Gao}

\author{
North China Electric Power University, Beijing, 102206 \\ alanncepu@foxmail.com
}

Keywords: Smart grid; New energy; Distributed generation; Self-Cure; Eco-City

\begin{abstract}
With the rapid development of the exploitation and utilization of renewable energy, the world is faced with a series of problems such as how to access and make full use of renewable energy. Smart grid is an effective strategic measure to respond to these challenges. Global research and construction of the smart grid has a very profound impact on the future development of electric power industry. Smart grid is the trend of the world's power grid development, which takes many superior services for tens of thousands of users because of its safety, reliability and efficiency. This article introduces the definition, characteristics, technical connotation and research progress of smart grid and makes some suggestions for the future development of smart grid.
\end{abstract}

\section{The Definition of the Smart Grid}

With the accelerating pace of global economic growth, rapid development of electric power technology, the increasingly serious energy crisis, the improving power market, the increasing demand of users for electricity services, the phrase "smart grid" came into being. Smart grid is the intelligent grid, also known as the knowledge grid. It is communication technology and a new type of highly integrated grid of power supply and power distribution infrastructure, based on the high-speed two-way communication network and combined with information technology and computer technology. It has such advantages as self-healing, security, controllability, objectivity and fastness.

The distribution of China's primary energy and load center is extremely uneven, which leads to the need for transmission of electric power from power center to load center in a manner of long distance and large capacity with the use of Ultra-High Voltage as the backbone. So our country proposes the definition of smart grid with Chinese characteristics. State Grid Corporation initially put forward the concept of "strong smart grid", which intends to use UHV power grid as the backbone grid and a strong grid of coordinated development at all levels as the foundation. It will take advantage of advanced technologies of communication, information, and control to build a strong intelligent power grid with features of informatization, automation, and interaction, embodying independent innovation, internationally leading level, and Chinese characteristics.

The smart grid can bring benefits not only to the grid, but also to all consumers and the whole community. Research has shown that the economic and environmental benefits brought by changing current power grid into a smart grid outweigh the required investment. From the economic perspective, users can make full use of electricity at less expensive prices during off-peak hours. Total energy consumption will be reduced by involving users in load management. From the environmental protection perspective, smart grid can reduce the amount of carbide emissions by reducing the peak load under the premise of meeting load demand. Besides, new energy power generation has become an important part of the smart grid to replace some of the traditional power and improve the quality of the environment.

\section{The Characteristics of the Smart Grid}

Self-Healing. When a fault happens, the equipment of the smart grid should send a message in time according to the fault type and take the right measures to minimize the loss of the fault brings to the grid. Grid basal system and technical support system is perfect, which could make a good defense for interference and attacks. After the access to the new type of sustainable energy, the 
dependability of power grid has increased dramatically.

The smart grid could also be able to distinguish the natural destruction and man-made destruction and make corresponding responses, especially in preventing the failure of computer virus and ensuring the security of information. Due to the fusion of technical integration, such as computer information technology, sensor technology, and network technology, the smart grid has a strong ability to recover automatically when faced with disaster and failure.

Miraculous Property. The smart grid could optimize the use of assets and reduce the cost of investment and operating maintenance. Asset optimization includes the dispatch of distribution and regional transmission in different range and balance the power supply gap. The performance of enterprises could be enhanced by optimizing process, integrating information and arranging maintenance and overhaul of equipment.

Users Participation. Nowadays, users are not involved in the power management system. While in the smart grid, users could actively choose when to use power based on different electricity price in different time. A two-way interactive platform will be established to make electric power company get the user's detailed information timely and provide users with more convenient value-added services. Besides, the users can know more about the quality of electric energy and information about fault lines and peak power. It intervene and influence power users' behavior of using power through two ways as time-of-use power price and bidirectional information. Thus to balance users' consumption of electricity and to avoid power problems such as mains breakdown in peak season. Users also allowed to make small fan and the family solar panels connected to the electricity grid to send electricity to the grid, which makes using power bidirectional and interactive.

Resistance of the Natural Disasters. At present, power grid is very fragile when faced with danger and natural disasters. While smart grid should be able to resist the some disaster. On the one side, whether smart grid is under the artificial damage, or natural disasters and extreme climate conditions, the grid will still maintain safe operation. On the other side, even in the case of large disturbance and failure, smart grid can also provide users with the normal power supply and prevent widespread blackouts accidents.

Introduction of Distributed Generation. In addition to the conventional large power plants in the smart grid, there should be a large number of distributed power supply, power electronics, and energy storage devices. The distributed power is usually new energy power generation. They can optimize the grid system, improve the energy efficiency and reduce power loss, making the power production and management more efficient.

\section{The Technical Connotation of Smart Grid}

The smart grid will strengthen many aspects of power switching system, such as power generation, transmission, distribution, and consumption. Compared with the existing grid, smart grid reflects its outstanding feature to mix the power flow, information flow and business flow together.

There are some concrete aspects of smart grid:

(1)Provide a wide range of situation awareness. The work will be helpful to ease the grid block and bottlenecks, get the whole scene information of the grid and timely discovery the possibility of failure. It could identify and response to the destruction of man-made or natural disaster to prevent blackouts.

(2)Provide a better system observability for grid operators, enabling them to optimize flow control and asset management and making the power grid has the ability of self-healing and quick recovery after accident. The power grid operation control will be more flexible and economic.

(3)Support a variety of large-scale application of energy, which can not only make different power access at the same time, but also make a timely use of electricity produced by distributed power generation.

(4)Provide consumers with the opportunity and make them actively participate in energy option. By establishing a two-way interactive service mode, users can get information of the status of the power supply ability, power quality, price and power outage, and then make reasonable arrangement 
of electric equipment use. Besides, the electric power enterprise can obtain the user's information of using electricity in detail to provide more value-added services for them.

\section{Domestic Research Progress}

Smart grid construction in China is divided into three phases, According to the plan, a comprehensive strong smart grid will be built in 2020 .

From 2009 to 2010 is the stage for planning pilot, the main task is to make plans for smart grid, develop management and technical standards, research key technology and develop the main equipment.

From 2011 to 2015 is the stage for overall construction. During this period, we are supposed to accelerate the construction of extra-high voltage and distribution network and achieve a major breakthrough in the key technology and equipment to have the initial formation of the smart grid service system and achieve a major breakthrough on the key technology and equipment use.

From 2016 to 2020 is the stage for promotion. A unified strong smart grid will be fully completed to promote the grid's resource allocation ability, safety, efficiency, and the interaction between power grid and users. At that time, the grid will play a more important role in clean energy development, energy supply and promotion of economy and society development.

To take the summary smart grid integrated demonstration project of sino-Singapore Tianjin Eco-City as an example. It covers six links of the smart grid and is the demonstration project to fuse smart grid to Eco-city.

It is the second cooperation development project between China and Singapore and is the largest comprehensive smart grid demonstration area in the world. As the second batch of national grid company's strong smart grid integrated demonstration project, the comprehensive utilization of renewable energy and protection of the ecological environment has attracted highly attention. Ecology, environmental protection and green is an important development direction of it.

According to the goals for engineering construction, construction ideas are put forward as follows:

1. A strong, flexible and reconfigurable distribution network topology is the foundation of Eco-city intelligent power grid.

2. To establish a unified communication information network and build a "Eco-city smart grid city" communication network based on high-speed broadband and wireless sensor network.

3. To make intelligent power distribution automation and intelligent dispatch come true and realize the intelligent control of overall level.

4. To carry out two-way interactive service, realize the positive interaction and mutual coordination between power supply, power grid and the users, and then optimize allocation of resources.

The project pays attention to system construction and establish a sustainable development system which runs through power generation, transmission, substation, distribution, utilization and scheduling, supported by information communication platform. Each link joins effectively and cooperate with each other, showing advanced characters of smart grid such as informatization, automation and interaction.

\section{Advice on Future Implementation of the Smart Gird}

The Smart Grid will Turn a Centralized, Producer-Controlled Grid into a Large Number of Distributed Networks which Interact with More Consumers. The process of grid transformation will change the business model of the industry as a whole and benefit all stakeholders. In future development, the smart grid should pay more attention to the improvement of the distribution network and the optimization of the operation. It should also give full attention to the access control of distributed power sources, and put efficiency and environmental protection as the ultimate goal and direction. 
The Smart Grid is an Evolving Goal that Requires Ongoing Research to Predict Constantly Changing Needs and Assess the Ever-Changing Benefits and Costs. Power companies and regulators should continually demonstrate to consumers that the benefits of smart grids will eventually exceed its costs.

In the Implementation of Smart Grid, we must adhere to the Strategy of "Innovation-Driven Development". The obtainment of a large number of intellectual property rights should be concerned. A lot of innovations should be made in aspects of smart grid technologies, technologies that can be driven by smart grid, and technologies employed to create platforms for smart grid.

The Nature of the Smart Grid Determines that its Participants should not be Confined to Power Companies and Power Equipment Manufacturers. Vast number of consumers and many other industries should also be involved. Therefore, the state needs to develop appropriate policies and standards in an open manner to encourage and support the participation of many enterprises.

As the smart grid can greatly improve the efficiency of energy use and present broad prospects, some people think that home appliances and electric vehicles will also be equipped with smart meters and communication functions in the near future.

Smart grid is a huge systematic project which requires advanced technology and great economic strength. Although the smart grid has become the international direction of the development of power industry, problems still exist, including immature development at the overall level and the lack of national key investments. Besides, the technologies remain to be further studied, and the development focus varies across the countries. For China, the construction of the smart grid carries great significance for enhancing the quality of life of residents, improving the level of service of power system, achieving safe operation of the grid, realizing energy-saving and low-carbon environmental protection, and promoting social and economic development.

\section{References}

[1] Chen S Y, Song S F, Lan-Xin L I, et al. Survey on Smart Grid Technology [J]. Power System Technology, 2009, 33(8):1-7.

[2] Xie K, Liu Y Q, Zhu Z Z, et al. The vision of future smart grid [J]. Electric Power, 2008.

[3] Xie W, Wang W, Zhang Z, et al. Exhibition on Strong \& Smart Grid Theme of the State Grid Pavilion in Expo [J]. Distribution \& Utilization, 2010.

[4]Davidson J E, Downing C L. Contemporary models of intelligence [J]. Robert J Sternberg, 2004: págs. 34-52.

[5] Yi-Xin Y U, Luan W P. Smart Grid [J]. Power System \& Clean Energy, 2009, 127(9):251-253.

[6] Council S T. A Policy Framework for the 21st Century Grid - A Progress Report - February 2013[C]// IEEE USA Books \& eBooks, 2013:11.

[7] Liu Y X, Niu Y L, Zhang J C. Contrastive Analysis of Smart Grid Development Pattern at Home and Abroad [J]. Henan Electric Power, 2011.

[8] Giordano V, Gangale F, Jrcie G F, et al. Smart Grid projects in Europe: lessons learned and current developments [J]. 2013.

[9] Zou Y, Xu X H, Wang Y, et al. Model Research on the Whole Industry Chain Value Analysis of Strong and Smart Grid[J]. Advanced Materials Research, 2014, 1070-1072:1346-1354.

[10] Seyedfarshi S, Pourmostadam K. The challenges in developing a smart grid roadmap for the distribution network of $\operatorname{Iran}[\mathrm{C}] / /$ International Conference and Exhibition on Electricity Distribution. 2013:1-4. 